\title{
Stochastic forecasting of the state of the soil under the roadbed
}

\author{
Klavdiia A. Spasennikova, ${ }^{1, *}$, Gennady V. Anikin ${ }^{1}$, Anatoliy A. Gubarkov² \\ ${ }^{1}$ Institute of Earth Cryosphere FRC Tyumen SC SB RAS, 625000, Tyumen, P/O box 1230, Russia \\ ${ }^{2}$ Industrial University of Tyumen, 625000, Tyumen, Russia
}

\begin{abstract}
The stochastic forecasting method was used to simulate the state of the soil under the roadbed for a period of four years. It is shown that the probability of finding soil in the thawed state with a thermal insulator is $0 \%$ and without a thermal insulator is $70 \%$.
\end{abstract}

\section{Introduction}

Currently active development of natural and energy resources of the Arctic zone is being carried out. This process is closely connected with the construction of roads on the soil grounds of the cryolithozone and is accompanied by an active change in the natural thermal regime of permafrost.

To prevent deformation of roads built in the permafrost zone, a thermal insulator, usually penoplex, is placed under the roadway. To understand how much this is necessary, we conducted a stochastic forecasting of the soil condition under the embankment of the roadway and calculated the temperature fields below it for two cases: 1-thermo-insulator is absent; 2 thermo-insulator - penoplex. The calculation was carried out in accordance with the methodology described in the works [1-8].

\section{Formulation of the problem}

We consider the roadway, which is depicted in Fig. 1

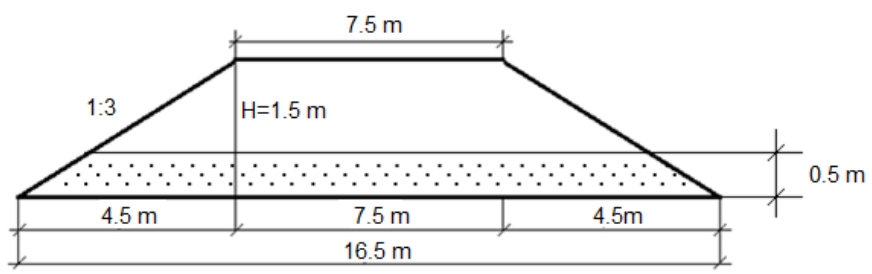

Fig. 1. Section of the roadway.

\footnotetext{
*Corresponding author: klavachka87@mail.ru
} 
In the first case, we calculated a mound with a height of $1.5 \mathrm{~m}$, in the second case a layer of penoplex $(0.5 \mathrm{~m})$ was added to the mound. The thermophysical parameters of the soil and penoplex used for calculation in the work are given in Table 1.

Table 1. Thermophysical parameters of soil and penoplex.

\begin{tabular}{|c|c|c|c|c|c|c|}
\hline & & $\begin{array}{c}\text { Thermal } \\
\text { conductivity } \\
\lambda(W / m \cdot \mathrm{K})\end{array}$ & $\begin{array}{c}\text { Volumetric } \\
\text { heat capacity } \\
\mathrm{C}\left(\mathrm{kJ} / \mathrm{m}^{3} \cdot \mathrm{K}\right)\end{array}$ & $\begin{array}{c}\text { Thermal } \\
\text { Diffusivity } \\
\mathrm{a}\left(\mathrm{m}^{2} / \mathrm{sec}\right)\end{array}$ & $\begin{array}{c}\text { Humidit } \\
\mathrm{y}\end{array}$ & $\begin{array}{c}\text { Skeletal } \\
\text { density } \\
\gamma_{s \kappa}\left(\mathrm{kg} / \mathrm{m}^{3}\right)\end{array}$ \\
\hline 1 & $\begin{array}{c}\text { Frozen } \\
\text { soil }\end{array}$ & 2 & 2985 & $0.67 \cdot 10^{-6}$ & 0.25 & 1620 \\
\hline 2 & $\begin{array}{c}\text { Meltdow } \\
\text { n soil }\end{array}$ & 1,4 & 3043 & $0.46 \cdot 10^{-6}$ & 0.25 & 1620 \\
\hline 3 & Penoplex & 0,03 & 46.4 & $646.6 \cdot 10^{-6}$ & 0 & 32 \\
\hline
\end{tabular}

Climate information from Igarka meteorological station was used. The distributions of the probabilities for temperature, wind speed and snow cover for each of the twelve months of the year are described in detail in the paper [9].

The calculated area of $20 \mathrm{~m} \times 100 \mathrm{~m} \times 100 \mathrm{~m}$ size is specified by the following nodes:

$$
\begin{array}{cc}
x_{i}=i \cdot 0.1, & 0 \leq i \leq 199, \\
y_{j}=j \cdot 0.1, & 0 \leq j \leq 1001, \\
z_{k}=k \cdot 1, & 0 \leq k \leq 99
\end{array}
$$

By using a pseudo-random number generator written with MathCAD-14, we generate an array of numbers $48 \times 48$ in size. Thus, 48 variants of change in meteorological characteristics with a duration of 48 months or 4 years each are obtained. Starting the calculation from the beginning of September and ending with the end of August for each of the 48 variants of the development of events, we get 48 three-dimensional temperature fields at the end of August.

The temperature at the lower boundary of the calculated region was assumed to be $-1.4^{\circ} \mathrm{C}$.

The calculation was carried out on the computer NKS-30T of the Siberian supercomputer center.

Having obtained 48 three-dimensional temperature fields at the end of August of the 4th calculation year, we will single out a line (No. 1) passing through the center of the road, perpendicular to it. We calculate the temperatures on the line No. 1, at points, each of which is given by the following coordinates in the computational domain: $x=x_{j}(0 \leq j \leq$ 11) $\mathrm{m}, \mathrm{y}=50 \mathrm{~m}, \mathrm{z}=50 \mathrm{~m}$

We also calculate the temperatures on the line (No. 2) of the parallel surface, but perpendicular to the mound of the road passing through the points defined by the following coordinates in the calculation area: $\mathrm{x}=2.0 \mathrm{~m}, \mathrm{y}=\mathrm{y}_{\mathrm{i}}(0 \leq \mathrm{i} \leq 23) \mathrm{m}, \mathrm{z}=50 \mathrm{~m}$ (see Figure 1).

The values of $x_{j}$ are given in Table 2, and the values of $y_{i}$ in Table 3.

Now let's estimate the probability of finding the ground in the thawed state on lines 1 and 2 . By stochastic forecasting, using several hundred different variants, in the works $[13,14]$ it was shown that the distribution of temperatures in the soil at each spatial point has the form of a normal distribution, and a sample of 48 variants yields the same distribution options as the general population. The probability $W c_{j}$ of finding the temperature $t>T_{b f}$ at the point with the number $\mathrm{j}$ on the line No. 1 is given by the following expression [10-12]: 


$$
W c_{j}=100 \% \cdot \int_{T_{b f}}^{+\infty} \frac{\exp \left(-\left(t-\overline{t c}_{j}\right)^{2} / 2 \overline{\sigma c}_{j}^{2}\right)}{\overline{\sigma c}_{j} \sqrt{2 \pi}} d t
$$

Where $t$ are the temperatures (in the range from $T_{b f}$ to $+\infty{ }^{\circ} \mathrm{C}$ ), the probability of which is found at node $\mathrm{j}, \overline{\mathrm{tc}}_{\mathrm{j}}, \overline{\sigma \mathrm{c}}_{\mathrm{j}}$ is the mathematical expectation and root-mean-square deviation of soil temperature at node $\mathrm{j}$.

$$
\overline{t c}_{j}=\sum_{k=1}^{48} \frac{t c_{k, j}}{48}, \quad \overline{\sigma c}_{j}=\sqrt{\sum_{k=1}^{48} \frac{\left(t c_{k, j}-\overline{t c}_{j}\right)^{2}}{48}}
$$

Where $t c_{k, j}$ is the temperature value at the point with the number $\mathrm{j}$ on the line No. 1 for a scenario with the number $\mathrm{k}$.

The formula for $W m_{i}>T_{b f}$ on line No. 2 is identical except for the letter designation [15]:

$$
\begin{gathered}
W m_{i}=100 \% \cdot \int_{T_{b f}}^{+\infty} \frac{\exp \left(-\left(t-\overline{t m}_{i}\right)^{2} / 2 \overline{\sigma m}_{i}^{2}\right)}{\overline{\sigma m}_{i} \sqrt{2 \pi}} d t \\
\overline{t m}_{i}=\sum_{k=1}^{48} \frac{t m_{k, i}}{48}, \quad \overline{\sigma m}_{i}=\sqrt{\sum_{k=1}^{48} \frac{\left(t m_{k, i}-\overline{t m}_{i}\right)^{2}}{48}}
\end{gathered}
$$

Where $t m_{k, i}$ is the temperature value at the point with the number $\mathrm{i}$ on line No. 2 for the variant of the development of events with the number $\mathrm{k}$.

Where $t$ are the temperature values (in the range from $T_{b f}$ to $+\infty{ }^{\circ} \mathrm{C}$ ), the probability of which is found at node $i, \overline{\mathrm{tm}}_{\mathrm{i}}, \overline{\sigma \mathrm{m}}_{\mathrm{i}}$ is the mathematical expectation and root-mean-square deviation of soil temperature at node $i$.

Carrying out the calculations using formulas (1) and (3), we obtain Table 2 for $\mathrm{Wc}_{\mathrm{j}}$ and Table 3 for $\mathrm{Wm}_{\mathrm{i}}$ for the case with penoplex.

Table 2. The values of $\left(\mathrm{x}_{\mathrm{j}}\right)$ and the probability $\left(\mathrm{Wc}_{\mathrm{j}}\right)$ of finding the ground in the thawed state at the end of August of the 4th calculation year, on line No. 1. For the case with penoplex.

\begin{tabular}{|c|c|c|c|c|c|c|}
\hline $\mathbf{j}$ & $\mathbf{0}$ & $\mathbf{1}$ & $\mathbf{2}$ & $\mathbf{3}$ & $\mathbf{4}$ & $\mathbf{5}$ \\
\hline $\mathrm{x}_{\mathrm{j}}, \mathrm{m}$ & 0.7 & 1.2 & 1.7 & 2.2 & 2.7 & 3.2 \\
\hline $\mathrm{Wc}_{\mathrm{j}}, \%$ & 95.5 & 48.5 & 0 & 0 & 0 & 0 \\
\hline $\mathbf{j}$ & $\mathbf{6}$ & $\mathbf{7}$ & $\mathbf{8}$ & $\mathbf{9}$ & $\mathbf{1 0}$ & $\mathbf{1 1}$ \\
\hline $\mathrm{x}_{\mathbf{j}}, \mathrm{m}$ & 4.2 & 5.2 & 6.2 & 7.2 & 8.2 & 9.2 \\
\hline $\mathrm{Wc}_{\mathrm{j}}, \%$ & 0.002 & 0 & 0 & 0 & 0 & 0 \\
\hline
\end{tabular}

Table 3. The values of $\left.y_{i}\right)$ and the probability $\left(\mathrm{Wm}_{\mathrm{i}}\right)$ of finding the ground in the thawed state at the end of August of the 4th calculation year, on line No. 2. For the case with penoplex.

\begin{tabular}{|c|c|c|c|c|c|c|}
\hline $\mathbf{i}$ & $\mathbf{0}$ & $\mathbf{1}$ & $\mathbf{2}$ & $\mathbf{3}$ & $\mathbf{4}$ & $\mathbf{5}$ \\
\hline $\mathrm{Wm}_{\mathrm{i}}, \%$ & 95.51 & 95.51 & 95.51 & 95.52 & 95.54 & 95.57 \\
\hline $\mathrm{y}_{\mathrm{i}}, \mathrm{m}$ & 17 & 20 & 23 & 26 & 29 & 32 \\
\hline $\mathbf{i}$ & $\mathbf{6}$ & $\mathbf{7}$ & $\mathbf{8}$ & $\mathbf{9}$ & $\mathbf{1 0}$ & $\mathbf{1 1}$ \\
\hline $\mathrm{y}_{\mathrm{i}}, \mathrm{m}$ & 35 & 38 & 41 & 44 & 47 & 50 \\
\hline
\end{tabular}




\begin{tabular}{|c|c|c|c|c|c|c|}
\hline $\mathrm{Wm}_{\mathrm{i}}, \%$ & 95.66 & 95.76 & 93.93 & 0 & 0 & 0 \\
\hline $\mathbf{i}$ & $\mathbf{1 2}$ & $\mathbf{1 3}$ & $\mathbf{1 4}$ & $\mathbf{1 5}$ & $\mathbf{1 6}$ & $\mathbf{1 7}$ \\
\hline $\mathrm{y}_{\mathrm{i}}, \mathrm{m}$ & 53 & 56 & 59 & 62 & 65 & 68 \\
\hline $\mathrm{Wm}_{\mathrm{i}}, \%$ & 0 & 0 & 93.93 & 95.76 & 95.66 & 95.57 \\
\hline $\mathbf{i}$ & $\mathbf{1 8}$ & $\mathbf{1 9}$ & $\mathbf{2 0}$ & $\mathbf{2 1}$ & $\mathbf{2 2}$ & $\mathbf{2 3}$ \\
\hline $\mathrm{y}_{\mathrm{i}}, \mathrm{m}$ & 71 & 74 & 77 & 80 & 83 & 86 \\
\hline $\mathrm{Wm}_{\mathrm{i}}, \%$ & 95.54 & 95.52 & 95.51 & 95.51 & 95.51 & 95.51 \\
\hline
\end{tabular}

It can be seen from the tables that the probability of finding ground in the thawed state on line No. 1 is 0 percent.

Similarly, we obtain Table 4 for $\mathrm{Wc}_{\mathrm{j}}$ and Table 5 for $\mathrm{Wm}_{\mathrm{i}}$ for the case without Penoplex.

Table 4. The probability $\left(\mathrm{Wc}_{\mathrm{j}}\right)$ of finding the ground in the thawed state at the end of August of the 4th calculation year, on line No. 1. For the case without penoplex.

\begin{tabular}{|c|c|c|c|c|c|c|}
\hline $\boldsymbol{j}$ & $\mathbf{0}$ & $\mathbf{1}$ & $\mathbf{2}$ & $\mathbf{3}$ & $\mathbf{4}$ & $\mathbf{5}$ \\
\hline $\mathrm{Wc}_{\mathrm{j}}, \%$ & 95.26 & 94.28 & 83.52 & 38.87 & 2.33 & 0 \\
\hline $\mathbf{j}$ & $\mathbf{6}$ & $\mathbf{7}$ & $\mathbf{8}$ & $\mathbf{9}$ & $\mathbf{1 0}$ & $\mathbf{1 1}$ \\
\hline $\mathrm{Wc}_{\mathrm{j}}, \%$ & 0 & 0 & 0 & 0 & 0 & 0 \\
\hline
\end{tabular}

Table 5. The probability of finding the ground in the thawed state at the end of August of the 4th calculation year, on line No. 2. For the case without penoplex.

\begin{tabular}{|c|c|c|c|c|c|c|}
\hline$i$ & $\mathbf{0}$ & 1 & 2 & $\mathbf{3}$ & 4 & 5 \\
\hline $\mathrm{Wm}_{\mathrm{i}}, \%$ & 95.5 & 95.51 & 95.51 & 95.51 & 95.52 & 95.54 \\
\hline$i$ & 6 & 7 & 8 & 9 & 10 & 11 \\
\hline $\mathrm{Wm}_{\mathrm{i}}, \%$ & 95.58 & 95.66 & 95.19 & 90.5 & 69.97 & 71.68 \\
\hline $\mathbf{i}$ & 12 & 13 & 14 & 15 & 16 & 17 \\
\hline $\mathrm{Wm}_{\mathrm{i}}, \%$ & 69.97 & 90.5 & 95.19 & 95.66 & 95.58 & 95.54 \\
\hline$i$ & 18 & 19 & 20 & 21 & 22 & 23 \\
\hline $\mathrm{Wm}_{\mathrm{i}}, \%$ & 95.52 & 95.51 & 95.51 & 95.51 & 95.51 & 95.5 \\
\hline
\end{tabular}

It can be seen from the tables that the probability of finding ground in the thawed state on line No. 2 is about 70 percent.

Further in Fig. 2 shows the temperature comparison charts for the coldest, warmest options and averaged over all options.

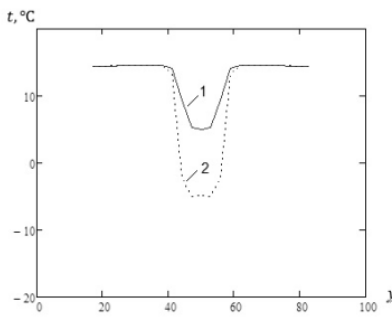

a

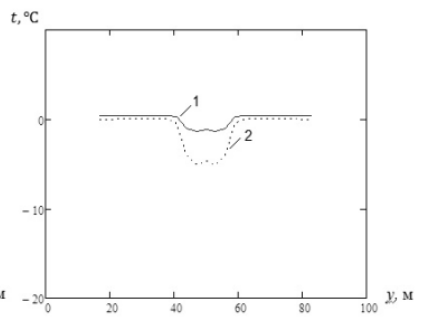

b

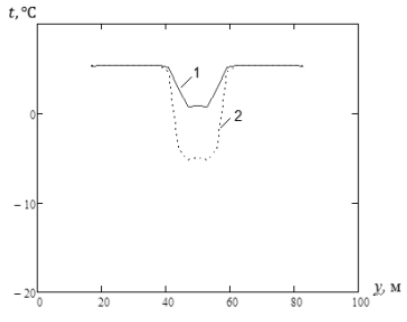

c

Fig. 2. Comparison of temperatures under the roadway: $a$ - for the warmest variant; $b$ - for the coldest version; $\mathrm{c}$ - averaged over all options. 1 - without penoplex; 2 - with penoplex. The y $(\mathrm{m})$ coordinate is plotted along the horizontal axis, and the temperature $\left({ }^{\circ} \mathrm{C}\right)$ is plotted along the vertical axis.

The temperature fields of the cut out part of the calculation area of $20 \mathrm{~m}$ wide are shown in Figures 3-4 for clarity. Figure 3 shows the thermal fields for the warmest variant in the 
case of penoplex and without, similarly in Fig. 4, thermo fields for the coldest version are shown.

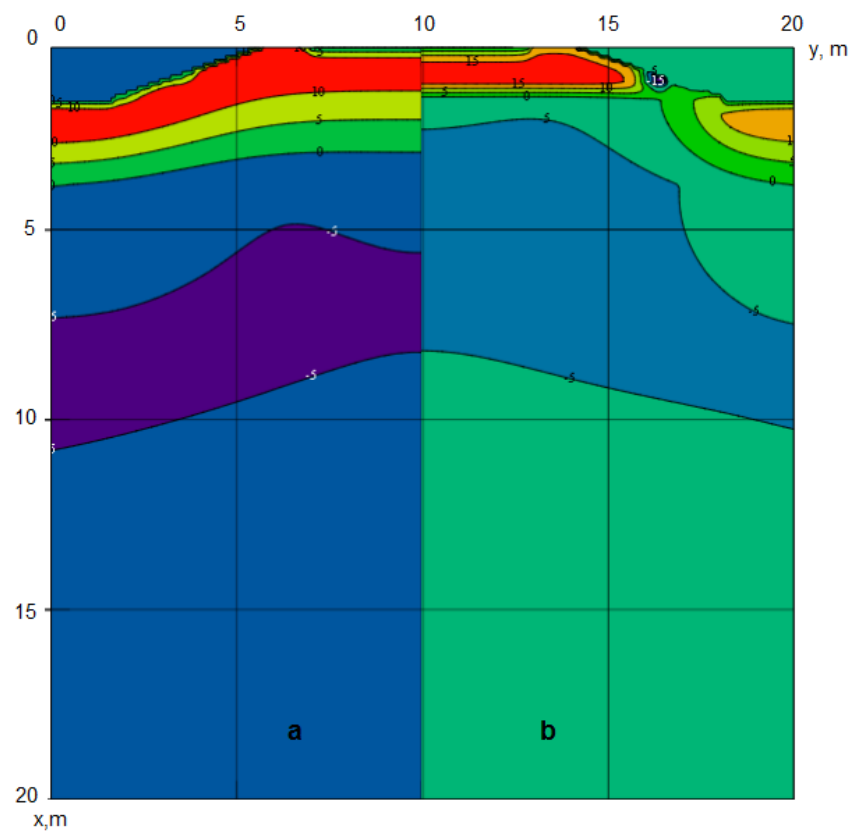

Fig. 3. Temperature field for the warmest variant: a - variant without penoplex (47); b - variant with penoplex (47). The $\mathrm{y}(\mathrm{m})$ coordinate is plotted along the horizontal axis, and the $\mathrm{x}(\mathrm{m})$ coordinate is plotted along the vertical axis.

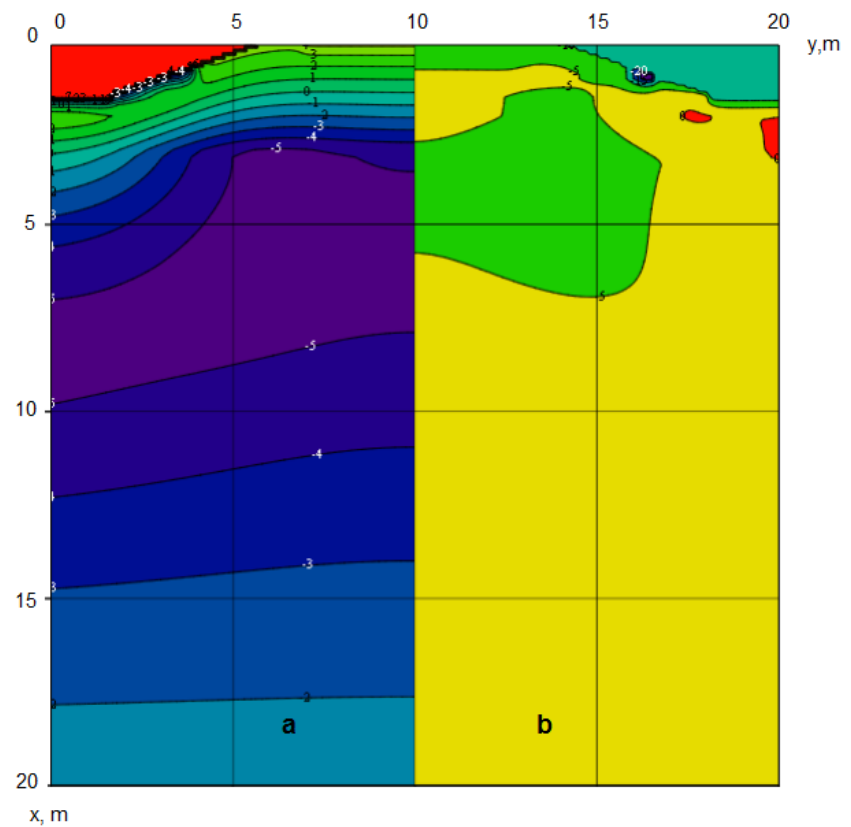

Fig. 4. Temperature field for the coldest variant: a - variant without penoplex (40); b - variant with penoplex (1). The $\mathrm{y}(\mathrm{m})$ coordinate is plotted along the horizontal axis, and the $\mathrm{x}(\mathrm{m})$ coordinate is plotted along the vertical axis. 


\section{Conclusion}

Penoplex demonstrated itself as a thermal insulation for the preservation of soil in the frozen state under the roadway.

\section{Acknowledgments}

This work was supported by the Basic Research Program of the Russian Academy of Sciences, project IX.135.2.4.

The results of calculations performed on the supercomputer NKS-30T of the Siberian supercomputer center were processed with the financial support of the Russian Foundation for Basic Research in the framework of the scientific project No. 18-38-00068.

\section{References}

1. G.V. Anikin, K.A. Spasennikova, Kriosfera Zemli 16, 60-64 (2012)

2. G.V. Anikin, S.N. Plotnikov, K.A. Spasennikova, Kriosfera Zemli 15, 33-39 (2011)

3. G.V. Anikin, S.N. Plotnikov, A.A. Vakulin, K.A. Spasennikova, Vestnik Tyumenskogo gosudarstvennogo universiteta 284, 35 (2009)

4. G.M. Dolgikh, G.V. Anikin, I.P. Rilo, K.A. Spasennikova, Kriosfera Zemli 19, 70-77 (2015)

5. G.M. Dolgikh, S.N. Okunev, G.V. Anikin, K.A. Spasennikova, K.V. Zalesski, Kriosfera Zemli 18, 65-70 (2014)

6. G.M. Dolgikh, S.N. Okunev, G.V. Anikin, K.A. Spasennikova, Kriosfera Zemli 17, 7076 (2013)

7. V.P. Melnikov, A.A. Melnikova, G.V. Anikin, K.S. Ivanov, K.A. Spasennikova, Kriosfera Zemli 18, 82-90 (2014)

8. K.A. Spasennikova, PhD Thesis (2015)

9. G.V. Anikin, K.A. Spasennikova, S.N. Plotnikov, A.A. Ishkov, Soil Mechanics and Foundation Engineering 1, 65-70 (2017)

10. G.V. Anikin, K.A. Spasennikova, S.N. Plotnikov, B.V. Grigoriev, P.Y. Mihailov, Kriosfera Zemli 21, 23-28 (2017)

11. G.V. Anikin, K.A. Spasennikova, S.N. Plotnikov, A.A. Ishkov, Soil Mechanics and Foundation Engineering 6, 30-34 (2017)

12. V.E. Gmurman, Teorija verojatnostej i matematicheskaja statistika (2002) 